Texte aus der Umwelt des Alten Testaments

Neue Folge 
Texte aus der Umwelt des Alten Testaments

\section{Neue Folge}

Begründet von

Otto Kaiser

Herausgegeben von

Bernd Janowski und Gernot Wilhelm

\section{in Verbindung mit}

Friedhelm Hartenstein, Karl Hecker, Andrea Jördens, Jörg Klinger, Heidemarie Koch, Ingo Kottsieper, Norbert Nebes, Hans Neumann, Herbert Niehr, Daniel Schwemer und Heike Sternberg-el Hotabi 


\section{Texte aus der Umwelt des Alten Testaments}

\section{Neue Folge}

\section{Band 3 \\ Briefe}

Angelika Berlejung, Louise Gestermann, Karl Hecker, Andrea Jördens, Michael Jursa, Jörg Klinger, Heidemarie Koch, Ingo Kottsieper, Jared L. Miller, Matthias Müller, Hans Neumann, Herbert Niehr, Carsten Peust, Rosel Pientka-Hinz, Karen Radner, Anson F. Rainey, Maren Schentuleit, Daniel Schwemer, Peter Stein, Gernot Wilhelm, Nele Ziegler

Redaktion: Michael Lichtenstein, Tübingen 
Bibliografische Information der Deutschen Nationalbibliothek

Die Deutsche Nationalbibliothek verzeichnet diese Publikation in der Deutschen Nationalbibliografie; detaillierte bibliografische Daten sind im Internet über https://portal.dnb.de abrufbar.

Copyright ( 2006 Gütersloher Verlagshaus, Gütersloh, in der Verlagsgruppe Random House $\mathrm{GmbH}$, Neumarkter Str. 28, 81673 München

Der Inhalt dieses E-Books ist urheberrechtlich geschützt und enthält technische Sicherungsmaßnahmen gegen unbefugte Nutzung. Die Entfernung dieser Sicherung sowie die Nutzung durch unbefugte Verarbeitung, Vervielfältigung, Verbreitung oder öffentliche Zugänglichmachung, insbesondere in elektronischer Form, ist untersagt und kann straf- und zivilrechtliche Sanktionen nach sich ziehen.

Der Verlag weist ausdrücklich darauf hin, dass im Text enthaltene externe Links vom Verlag nur bis zum Zeitpunkt der Buchveröffentlichung eingesehen werden konnten. Auf spätere Veränderungen hat der Verlag keinerlei Einfluss. Eine Haftung des Verlags ist daher ausgeschlossen.

Umschlaggestaltung: Init GmbH, Bielefeld

ISBN 978-3-641-21989-5

www.gtvh.de 